\title{
\& Journal of Oral Biology
}

Asmita Bhekare*, Mohamed Elghannam, Selina H Somji, Salvatore Florio and Takanori Suzuki

Department of Periodontology and Implant Dentistry, New York University, USA

\section{*Address for Correspondence}

Asmita Bhekare, Department of Periodontology and Implant Dentistry, New York University, Clinic 5W, 345 E 24th St, New York, NY 10010, USA, Tel: +1-929 294 3785; E-mail: Arb719@ nyu.edu

\section{Submission: 15 January, 2018}

Accepted: 20 April, 2018

Published: 27 April, 2018

Copyright: (๑) 2018 Bhekare A, et al. This is an open access article distributed under the Creative Commons Attribution License, which permits unrestricted use, distribution, and reproduction in any medium, provided the original work is properly cited.

Immediate implant placement; Immediate provisionalization: Anterior maxilla; Aesthetics

\section{Abstract}

Immediate implant placement and immediate provisionalization in the esthetic zone represents a therapeutic option particularly appreciated by patients. Reducing the number of surgical interventions and eliminating the need for a transitional removable prosthesis are clear advantages of this technique. However, performing this technique is not always possible and careful evaluation and case selection is crucial to achieve a predictable result. A 5 -factor decision tree is presented in order to successfully perform immediate implant placement and immediate provisionalization or select a more appropriate treatment modality according to the different clinical situation encountered.
\end{abstract}

\section{Introduction}

When having to replace a failing tooth in the esthetic zone, a dental implant is a predictable and successful treatment option that does not involve the preparation of adjacent teeth [1-2]. However, when compared to tooth-supported prostheses, dental implants usually require longer periods of treatment. Following tooth extraction, 12-16 weeks is typically needed to obtain substantial clinical or radiographic bone fill of the socket in order to place an implant [3]. An additional 3-6 months of sub mucosal healing prior to functional loading are essential for its osseointegration [4]. During this time interval, a removable provisional restoration can be used to replace the missing tooth but oftentimes, patients do not tolerate such prostheses well.

In order to reduce the duration of treatment, several variations to the conventional protocol have been reported in the literature [5-7]. The immediate implant placement and immediate provisionalization (IIPIP) technique involves placement of the implant immediately after tooth extraction and providing an implant-supported fixed restoration.

Numerous studies have shown that IIPIP attains high success rates comparable with single implants placed in healed sites that are either immediately provisionalized or treated with the conventional delayed loading approach [8-16]. Patients particularly appreciate this solution since it reduces the number of surgical interventions and eliminates the need for a temporary removable prosthesis.

Although the rationale behind immediate placement of
Table 1: Change of concepts of immediate implant placement and immediate provisionalization.

\begin{tabular}{|c|c|c|}
\hline Author & Year & Change of concepts \\
\hline Gelb DA [17] & 1993 & Open flap, bone graft+membrane, submerged \\
\hline Wohrle PS [18] & 1998 & $\begin{array}{c}\text { Atraumatic extraction and immediate } \\
\text { provisionalization }\end{array}$ \\
\hline Kan JY [19] & 2003 & Flapless surgery \\
\hline Kan JY [20] & 2011 & Apico-palatal bone for primary stability \\
\hline Su H [21] & 2010 & Concave emergence profile \\
\hline Chu SJ [22] & 2012 & Dual-zone concept \\
\hline
\end{tabular}

implants into fresh extraction sockets remains the same since it was reported by Gelb DA in 1993 the concept has evolved (Table 1) [17]. Establishing indistinguishable harmony between the restoration and the surrounding hard and soft tissues is crucial. However, achieving such a result may be challenging with IIPIP due to the hard tissue resorption and soft tissue recession that occurs [6,23-25]. Careful case selection and evaluation is therefore critical. The clinician must be aware of the biological and anatomical prerequisites that have to be met for IIPIP in the esthetic zone and select an alternative treatment option when these are not present or when intraoperative complications arise.

Despite being well documented, current guidelines and classifications can sometimes be too simple for all the parameters to be covered or far too complicated for a clinician to make the judgment on whether to perform this technique or not $[26,27]$.

The aim of this report is to guide the clinician with a 5 -factor decision tree during the diagnostic and surgical phases of the treatment to predictably and successfully perform IIPIP on a maxillary anterior tooth.

\section{Materials and Methods}

A search of the literature was performed focusing on immediate implant placement and immediate provisionalization. Clinical data in this study was obtained from the anonymous Implant Database (ID) at the Ashman Department of Periodontology and Implant Dentistry at the New York University College of Dentistry. This data was 
extracted as de-identified information from the routine treatment of patients. The ID was certified by the Health Insurance Portability and Accountability Act (HIPAA) and approved by the University Committee on the Activities Involving Human Subjects (UCAIHS). A computer search of electronic database from MEDLINE and PubMed at the Waldman Library at the NYUCD was performed. Keywords such as "immediate implant placement", "immediate provisionalization", "anterior maxilla", "aesthetics" were used, alone and in combination, to search the databases. Non-English language publications were excluded. The search was limited to studies involving human subjects. Restrictions were not placed regarding the type of study design.

\section{Case Presentation}

A 38-year old female patient presented with a fractured maxillary left central incisor as a result of trauma (Figure 1A). The patient was a non-smoker with an unremarkable medical history. Her chief complaint was to get her smile back to what it was. At the time of consultation, the patient was using an acrylic removable partial denture that she reported intolerance towards and she desired a fixed prosthesis (Figure 1B). The upper right maxillary incisor had a temporary crown. Clinical examination revealed a horizontal root fracture that deemed the tooth unrestorable.

No sign of active infection was noted from clinical and radiographic evaluation (Figure 1C). The surrounding soft tissue was healthy and the gum contour appeared harmonious with the adjacent teeth. Cone Beam Computed Tomography (CBCT) was taken which showed the full extent of the fracture (Figure 1D). Sagittal views showed adequate amount of apical and palatal bone to obtain primary stability for IIPIP. This treatment option was discussed with the patient and she was informed of the possible alternatives and potential intraoperative complications that could occur which may cause a modification to the treatment plan. The patient made an informed decision to go for immediate implant placement and immediate provisionalization. A wax-up was fabricated and shown to the patient (Figure 1E).

Antibiotic prophylaxis (Amoxicillin $2 \mathrm{~g}$ ) was administered 1 hour prior to the surgery. Following the administration of local anesthesia (2\% lidocaine with epinephrine 1:100,000, Septodont, CA) sharp dissection of the supracrestal fibers was performed with a $15 \mathrm{C}$ scalpel blade and the remaining root structure was extracted atraumatically so as not to cause any soft or hard tissue damage. The socket was thoroughly debrided with a surgical excavator and rinsed with saline. Socket integrity was then evaluated with a periodontal probe and the buccal bone plate was found to be $4 \mathrm{~mm}$ apical from the free gingival margin (Figure 1F). Implant osteotomy was performed based on the manufacturer's protocol under copious irrigation. A $4.3 \times 13 \mathrm{~mm}$ implant (Nobel Active, Nobel Biocare, Yorba Linda, CA) was placed so to engage at least $3 \mathrm{~mm}$ of the residual bone and maintain a $2 \mathrm{~mm}$ horizontal gap (Figure 1G). Primary stability was achieved which allowed for chair-side fabrication of a provisional restoration. A metal engaging temporary abutment was used (Nobel Biocare, Yorba Linda, CA).

Before delivering the provisional restoration, a xenograft bone graft material (small particle Bio-Oss, Geistlich Pharma, Princeton, NJ) was used to graft the horizontal gap between the implant and

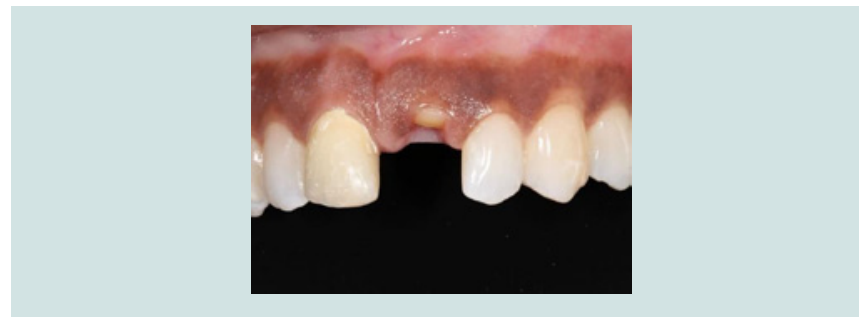

Figure 1A: Preoperative facial view of the temporary crown on the right central incisor and the fractured left maxillary central incisor.

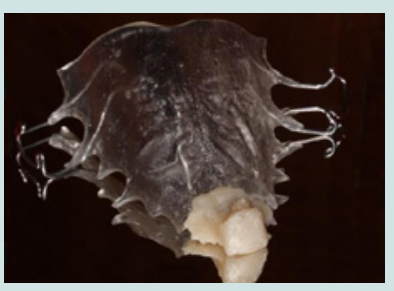

Figure 1B: Patient's removable partial denture.

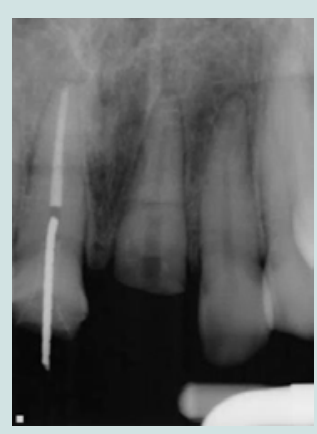

Figure 1C: Preoperative periapical radiograph of the fractured left maxillary central incisor. Note the horizontal root fracture.

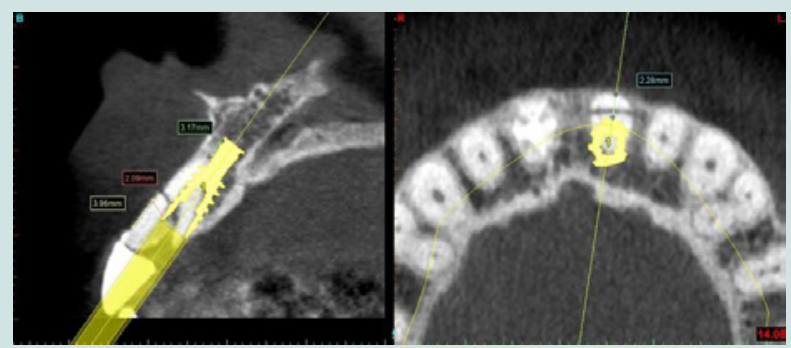

Figure 1D: Preoperative CBCT showing the sagittal and occlusal views with simulated implant placement.

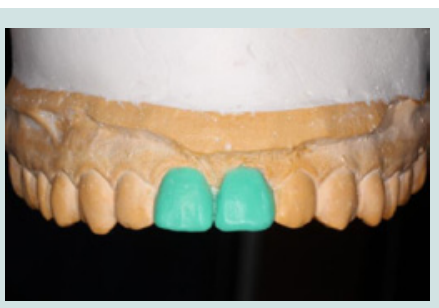

Figure 1E: Diagnostic wax up of the maxillary central incisors 
Citation: Bhekare A, Elghannam M, Somji SH, Florio S, Suzuki T. Case Selection Criteria for Predictable Immediate Implant Placement and Immediate Provisionalization. J Oral Biol. 2018; 5(1): 6

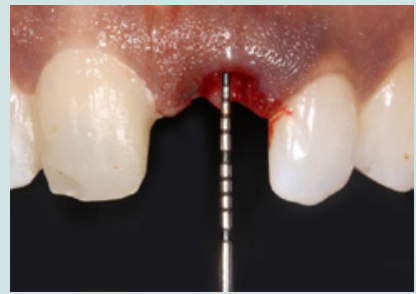

Figure 1F: Bone sounding of the extraction socket revealed the buccal plate to be $4 \mathrm{~mm}$ from the free gingival margin.

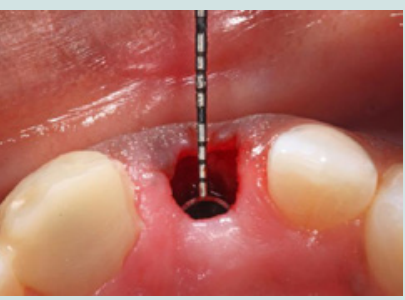

Figure 1G: A $2 \mathrm{~mm}$ horizontal gap between the implant and buccal plate was maintained.

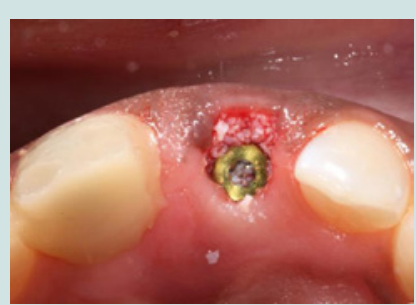

Figure 1H: Placement of the bone graft into the bone and tissue zones in the residual gap.

the buccal wall. Graft particles were inserted at the bone and the soft tissue level according to the dual-zone technique (Figure $1 \mathrm{H}$ ). The provisional restoration was hand tightened onto the implant and adjustments were made to ensure the prosthesis was out of occlusion (Figures 1I and 1J). Postoperative antibiotics and analgesia were prescribed for 7 days and the patient was asked to use $0.12 \%$ chlorhexidine (Peridex, Procter \& Gamble, Cincinnati, $\mathrm{OH}$ ) mouth rinse twice daily for 2 weeks. The patient was placed on a soft diet and followed up at 2 weeks, 4 weeks and 8 weeks. The healing was uneventful.

After an observation period of 5 months, the ridge was maintained (Figure 1K). A custom impression coping was fabricated to reproduce the emergence profile that had been established with the provisional restoration and the final impression was taken with polyvinylsiloxane. The definitive prosthesis was delivered and the patient reported complete satisfaction with the function and esthetics of her fixed restoration (Figures $1 \mathrm{~L}$ and $1 \mathrm{M}$ ).

\section{Discussion}

With success rates comparable with implants placed in healed sites, immediate implant placement and immediate provisionalization of a single anterior tooth is a viable option. Case selection is essential

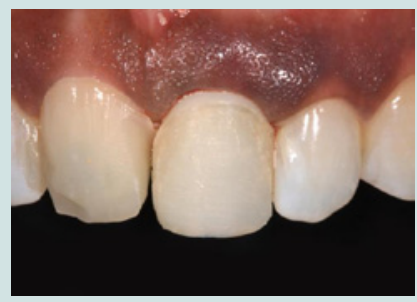

Figure 1I: Postoperative facial view of the provisional restoration. Note the preservation of the tissue architecture.

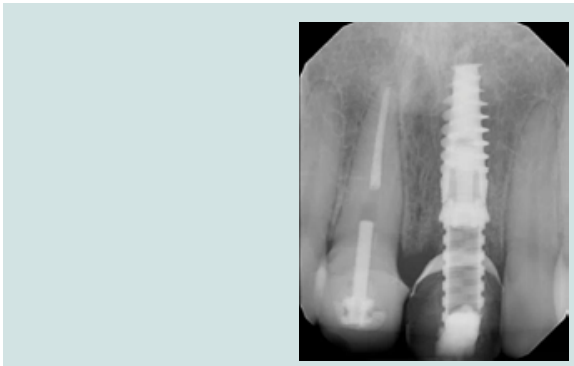

Figure 1J: Postoperative periapical radiograph with the provisional restoration in place.

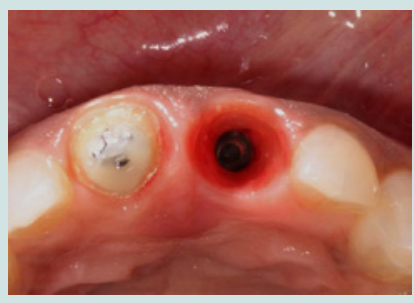

Figure 1K: The buccal-palatal ridge contour was maintained after 5 months.

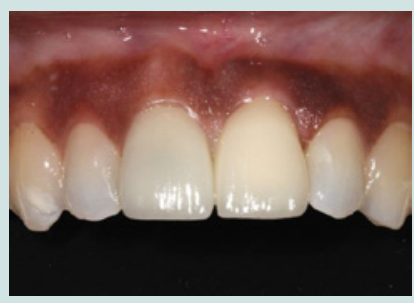

Figure 1L: Facial view of the definitive implant-supported restoration and tooth- supported restoration on the left and right central incisors respectively.

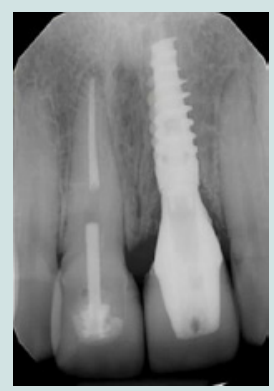

Figure 1M: Periapical radiograph after final delivery of prosthesis. 


\begin{tabular}{|c|}
\hline Hopeless Maxillary Anterior Tooth \\
\hline Absence of active infection \\
\hline Harmonious gingival contour \\
\hline Enough bone for primary stability \\
\hline Stable buccal plate for long-term tissue support \\
\hline Extraction and IIP \\
\hline Achieved initial stability \\
\hline Immediate Provisionalization \\
\hline IIPIP \\
\hline
\end{tabular}

Table 2: 5 Critical factors for immediate implant placement and immediate provisionalization.

and a predictable outcome is dependent on 5 critical factors (Table 2). The first 4 factors can be viewed as preoperative and the fifth factor as intraoperative.

\section{Critical factor 1: Absence of active infection}

It is generally accepted that implants should be placed in sites that are infection free [28]. When active purulent infection is present, placing an implant in such a site is contraindicated due the increased risk of failure [29]. However, it has been reported that immediate implant placement in sites exhibiting chronic periapical lesions can be a successful treatment modality with no disadvantages clinically, radio graphically or esthetically when compared to immediate implants in healthy sites [30,31].

In the presence of active infection, a delayed approach comprising of an atraumatic extraction together with thorough debridement of the infected socket and possible adjunctive antibiotics may be indicated to allow for resolution of infection in order to reduce the risk of complications.

\section{Critical factor 2: Harmonious gingival contour}

Careful evaluation of the periodontal form and gingival tissue level of the failing tooth must be made. Healthy gingival tissue that is in harmony with the neighboring dentition is a prerequisite for IIPIP. When ideal gingival contour is lacking, hard and/or soft tissue augmentation should be performed prior to, or simultaneous with implant placement in order to re-establish ideal soft tissue esthetics.

\section{Critical factor 3: Enough bone for primary stability}

Initial implant stability is essential for successful osseointegration. Achieving this is dependent on the apico-palatal bone volume present beyond the tooth root to allow for sufficient engagement of the implant. The amount of bone beyond the apex required to gain the critical element of stability is $3-5 \mathrm{~mm}[7,32]$. However, the proximity to vital structures such as the nasopalatine canal and the nasal floor can be a limiting factor that precludes IIPIP [33]. Root morphology can determine the feasibility of IIPIP and can be discerned by CBCT evaluation [20]. A favourable sagittal root position that allows for maximum engagement of the implant is desirable.

When the available bone around the failing tooth is deficient, a delayed approach is preferred. A decision can be made by the clinician to graft the socket at the time of extraction in order to limit the amount of bone remodeling or wait for natural healing of the socket.

\section{Critical factor 4: Stable buccal plate}

Type 1 extraction sockets, with intact buccal bone, have traditionally been favored for IIPIP [27]. The presence or absence of the buccal plate of bone can be determined by pre-operative CBCT. Maintaining this buccal plate is clinically significant to avoid midfacial recession and an atraumatic extraction is therefore fundamental [34]. More recently, immediate implant placement into sockets with dehiscence defects, however with a stable buccal plate, have been shown to give satisfactory results when a provisional restoration or custom contoured abutment is used concomitantly with a bone graft with or without a membrane [35-38].

When immediate placement of the implant is contraindicated, the clinician can perform a ridge preservation procedure or wait 4-8 weeks for complete soft tissue coverage of the socket (Figure 2). Early implant placement with simultaneous horizontal bone regeneration can then be performed to re-establish the buccal bone and cover the exposed implant threads (Figures 3A-3C).

\section{Critical factor 5: Primary stability}

Immediate provisionalization at the time of implant placement is solely dependent on whether primary stability is achieved or not. A clinical judgment should be made once the implant has been placed. The temporary cylinder is hand tightened onto the fixture until resistance is met. The clinician should be mindful to avoid overexertion while engaging the temporary cylinder. The provisional restoration can be fabricated in acrylic from the diagnostic wax up or if intact, the patient's own tooth can be used [39].

In situations where sufficient primary stability is not gained, immediate provisionalization is contraindicated since it would increase the risk of failure. In these cases, the buccal gap is still grafted and a custom healing abutment to support the free gingival margin is fabricated to seal the socket and maintain the graft particles in place (Figures $4 \mathrm{~A}$ and $4 \mathrm{~B}$ ).

\section{Conclusion}

Immediate implant placement and immediate provisionalization is a viable treatment option for a failing anterior tooth in the esthetic

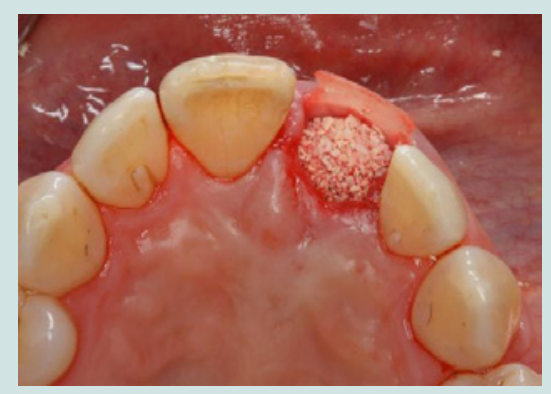

Figure 2: Socket grafting of an extraction socket using particulate allograft and a resorbable membrane. 
Citation: Bhekare A, Elghannam M, Somji SH, Florio S, Suzuki T. Case Selection Criteria for Predictable Immediate Implant Placement and Immediate Provisionalization. J Oral Biol. 2018; 5(1): 6

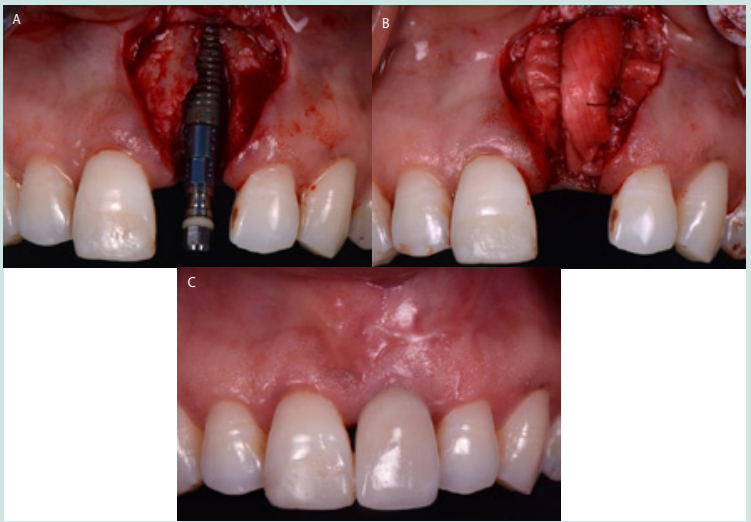

Figure 3: A: Implant placement 6 weeks after a maxillary left central incisor was extracted. Note the craterlike defect on the facial aspect of the implant. B The site is over-contoured with graft particles and covered with a resorbable collagen membrane. C: The aesthetic treatment outcome 6 months post loading.

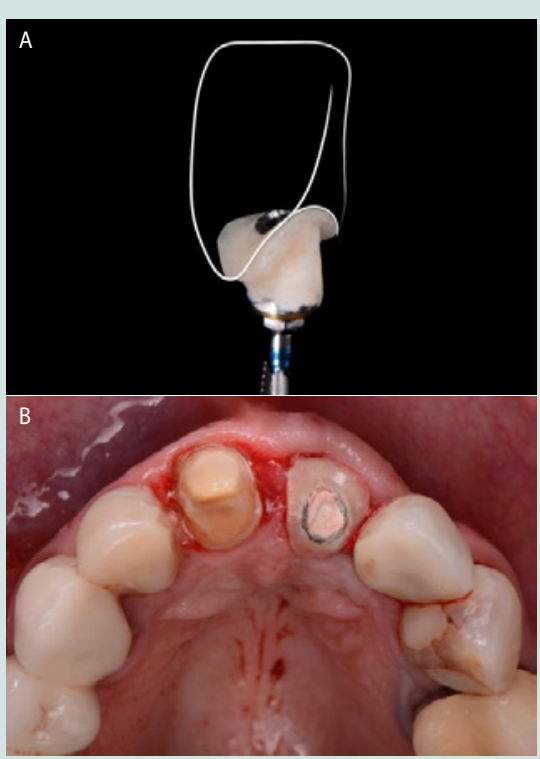

Figure 4: A: Customized healing abutments should capture the subgingival contours and pre-extraction state of the tooth cervix. B: A customized healing abutment in place.

zone. Despite the high success rates demonstrated with this treatment option, case selection and treatment planning are key. The 5 critical factors mentioned aid clinicians in achieving a predictable outcome when performing this technique. When conditions are not favorable, an alternative approach is advised.

\section{References}

1. Walton TR (2015) An up-to-15-year comparison of the survival and complication burden of three-unit tooth-supported fixed dental prostheses and implant-supported single crowns. Int J Oral Maxillofac Implants 30: 851861.

2. Salinas TJ, Eckert SE (2007) In patients requiring single-tooth replacement, what are the outcomes of implant-as compared to tooth-supported restorations? Int J Oral Maxillofac Implants 22 Suppl: 71-95.

3. Hammerle CH, Chen ST, Wilson TG Jr (2004) Consensus statements and recommended clinical procedures regarding the placement of implants in extraction sockets. Int J Oral Maxillofac Implants 19 Suppl: 26-28.

4. Albrektsson T, Brånemark PI, Hansson HA, Lindstrom J (1981) Osseointegrated titanium implants. Requirements for ensuring a long-lasting, direct bone-to-implant anchorage in man. Acta Orthop Scand 52: 155-170.

5. Buser D, Chen ST, Weber HP, Belser UC (2008) Early implant placement following single-tooth extraction in the esthetic zone: biologic rationale and surgical procedures. Int J Periodontics Restorative Dent 28: 441-451.

6. Chen ST, Buser D (2014) Esthetic outcomes following immediate and early implant placement in the anterior maxilla--a systematic review. Int $\mathrm{J}$ Oral Maxillofac Implants 29 Suppl: 186-215

7. Kan JY, Rungcharassaeng K (2000) Immediate placement and provisionalization of maxillary anterior single implants: a surgical and prosthodontic rationale. Pract Periodontics Aesthet Dent 12: 817-824.

8. Degidi M, Nardi D, Daprile G, Piattelli A (2012) Buccal bone plate in the immediately placed and restored maxillary single implant: a 7-year retrospective study using computed tomography. Implant Dent 21: 62-66.

9. Tarnow DP, Chu SJ, Salama MA, Stappert CF, Salama H, et al. (2014) Flapless postextraction socket implant placement in the esthetic zone: part 1. The effect of bone grafting and/or provisional restoration on facial-palatal ridge dimensional change-a retrospective cohort study. Int J Periodontics Restorative Dent 34: 323-331.

10. Barone A, Rispoli L, Vozza I, Quaranta A, Covani U (2006) Immediate restoration of single implants placed immediately after tooth extraction. J Periodontol 77: 1914-1920.

11. Crespi R, Cappare P, Gherlone E, Romanos GE (2008) Immediate versus delayed loading of dental implants placed in fresh extraction sockets in the maxillary esthetic zone: a clinical comparative study. Int J Oral Maxillofac Implants 23: 753-758

12. De Rouck T, Collys K, Cosyn J (2008) Immediate single-tooth implants in the anterior maxilla: a 1-year case cohort study on hard and soft tissue response. J Clin Periodontol 35: 649-657.

13. Andersen E, Haanaes HR, Knutsen BM (2002) Immediate loading of singletooth ITI implants in the anterior maxilla: a prospective 5-year pilot study. Clin Oral Implants Res 13: 281-287.

14. Cooper LF, Raes F, Reside GJ, Garriga JS, Tarrida LG, et al. (2010) Comparison of radiographic and clinical outcomes following immediate provisionalization of single-tooth dental implants placed in healed alveolar ridges and extraction sockets. Int J Oral Maxillofac Implants 25: 1222- 1232.

15. Romeo E, Chiapasco M, Ghisolfi M, Vogel G (2002) Long-term clinical effectiveness of oral implants in the treatment of partial edentulism. Sevenyear life table analysis of a prospective study with ITI dental implant system used for single-tooth restorations. Clin Oral Implants Res 13: 133-143.

16. Levin L, Sadet P, Grossman Y (2006) A retrospective evaluation of 1,387 single-tooth implants: a 6-year follow-up. J Periodontol 77: 2080-2083.

17. Gelb DA (1993) Immediate implant surgery: three-year retrospective evaluation of 50 consecutive cases. Int J Oral Maxillofac Implants 8: 388-399.

18. Wohrle PS (1998) Single-tooth replacement in the aesthetic zone with immediate provisionalization: fourteen consecutive case reports. Pract Periodontics Aesthet Dent 10: 1107-1114.

19. Kan JY, Rungcharassaeng K, Lozada J (2003) Immediate placement and provisionalization of maxillary anterior single implants: 1-year prospective study. Int J Oral Maxillofac Implants 18: 31-39.

20. Kan JY, Roe P, Rungcharassaeng K, Patel RD, Waki T, et al. (2011) Classification of sagittal root position in relation to the anterior maxillary osseous housing for immediate implant placement: a cone beam computed tomography study. Int J Oral Maxillofac Implants 26: 873-876.

21. Su H, González-Martín O, Weisgold A, Lee E (2010) Considerations of implant abutment and crown contour: critical contour and subcritical contour Int J Periodontics Restorative Dent 30: 335-343. 
Citation: Bhekare A, Elghannam M, Somji SH, Florio S, Suzuki T. Case Selection Criteria for Predictable Immediate Implant Placement and Immediate Provisionalization. J Oral Biol. 2018; 5(1): 6

22. Chu SJ, Salama MA, Salama H, Garber DA, Saito H, et al. (2012) The dualzone therapeutic concept of managing immediate implant placement and provisional restoration in anterior extraction sockets. Compend Contin Educ Dent 33: 524-532,534.

23. Araújo M, Sukekava F, Wennström J, Lindhe J (2006) Tissue modeling following implant placement in fresh extraction sockets. Clin Oral Implants Res 17: 615-624.

24. Sanz M, Cecchinato D, Ferrus J, Pjetursson EB, Lang NP, et al. (2010) A prospective, randomized-controlled clinical trial to evaluate bone preservation using implants with different geometry placed into extraction sockets in the maxilla. Clin Oral Implants Res 21: 13-21.

25. Hämmerle CH, Araújo MG, Simion M, Osteology Consensus Group 2011 (2012) Evidence-based knowledge on the biology and treatment of extraction sockets. Clin Oral Implants Res 23 Suppl 5: 80-82.

26. Elian N, Cho SC, Froum S, Smith RB, Tarnow DP (2007) A simplified socket classification and repair technique. Pract Proced Aesthet Dent 19: 99-104.

27. Juodzbalys G, Sakavicius D, Wang HL (2008) Classification of extraction sockets based upon soft and hard tissue components. J Periodontol 79: 413424.

28. Schwartz-Arad D, Chaushu G (1997) The ways and wherefores of immediate placement of implants into fresh extraction sites: a literature review. J Periodontol 68: 915-923.

29. Zhao D, Wu Y, Xu C, Zhang F (2016) Immediate dental implant placement into infected vs. non-infected sockets: a meta-analysis. Clin Oral Implants Res 27: 1290-1296.

30. Novaes AB Jr, Novaes AB (1995) Immediate implants placed into infected sites: a clinical report. Int J Oral Maxillofac Implants 10: 609-613.

31. Lee CT, Chuang SK, Stoupel J (2015) Survival analysis and other clinical outcomes of immediate implant placement in sites with periapical lesions: systematic review. Int J Oral Maxillofac Implants 30: 268-278.

32. Lang NP, Pun L, Lau KY, Li KY, Wong MC (2012) A systematic review on survival and success rates of implants placed immediately into fresh extraction sockets after at least 1 year. Clin Oral Implants Res 23 Suppl 5: 39-66.

33. Kan JY, Rungcharassaeng K, Roe $P$, Mesquida J, Chatriyanuyoke $P$, et al. (2012) Maxillary central incisor-incisive canal relationship: a cone beam computed tomography study. J Esthet Dent: 180-187.

34. Araújo MG, da Silva JC, de Mendonça AF, Lindhe J (2015) Ridge alterations following grafting of fresh extraction sockets in man. A randomized clinical trial. Clin Oral Implants Res 26: 407-412.

35. Noelken R, Kunkel M, Wagner W (2011) Immediate implant placement and provisionalization after long-axis root fracture and complete loss of the facial bony lamella. Int J Periodontics Restorative Dent 31: 175-183.

36. da Rosa JC, Rosa AC, da Rosa DM, Zardo CM (2013) Immediate dentoalveolar restoration of compromised sockets: a novel technique. Eur J Esthet Dent 8: 432-443.

37. Rosa JC, Rosa AC, Francischone CE, Sotto-Maior BS (2014) Esthetic outcomes and tissue stability of implant placement in compromised sockets following immediate dentoalveolar restoration: results of a prospective case series at 58 months follow-up. Int J Periodontics Restorative Dent 34:199208.

38. Sarnachiaro GO, Chu SJ, Sarnachiaro E, Gotta SL, Tarnow DP (2016) Immediate implant placement into extraction sockets with labial plate dehiscence defects: a clinical case series. Clin Implant Dent Relat Res 18: 821-829.

39. Wang WC, Suzuki T (2015) Utilization of extracted teeth as provisional restorations following immediate implant placement - a case report. Singapore Dent J 36: 23-28.
Acknowledgements

Special thanks to Dr. Margarida Sousa Menezes, DDS for her contribution of clinical cases and revision of the manuscript. 